\title{
Endoscopic Treatment in Chronic Pancreatitis
}

\author{
Yue Sun Cheung and Paul Bo-San Lai \\ Division of Hepato-biliary and Pancreatic Surgery, Department of Surgery, \\ The Chinese University of Hong Kong, Honk Kong, \\ China
}

\section{Introduction}

Chronic pancreatitis can give rise to relapsing episodic or persistent upper abdominal pain (Frulloni et al., 2010). Apart from the derangement of endocrine and exocrine functions, it can cause local complications such as pancreatic ductal stenosis, formation of intraductal stones and development of pseudocysts (Strobel et al., 2009). Management of these complications can be challenging in some patients. Various surgical drainage and resection procedures had been described with successful results (Strobel et al., 2009) but they were technically demanding and carried significant morbidities (Schnelldorfer et al., 2007). With the advancement in endoscopic treatments and novel techniques, some of the conventional open procedures have been replaced by endoscopic or minimally invasive techniques. In this chapter, we reviewed various endoscopic procedures available in treating patients with chronic pancreatitis, namely endoscopic sphincterotomy, stricture dilatation, stenting, stone extraction, endoscopic ultrasound-guided pseudocyst drainage and celiac plexus block. The indications, techniques and efficacy of endoscopic treatments were discussed in this chapter.

\section{Indications of endoscopic treatment}

Endoscopic treatment can be applied to different pathologic processes associated with chronic pancreatitis. These processes include pancreatic ductal strictures, stones and pancreatic pseudocyst formation (Sherman \& Lehman, 1998). These processes can lead to ductal obstruction and parenchymal hypertension, resulting in upper abdominal pain (Strobel et al., 2009). Restoration of the drainage of the main pancreatic duct by a combination of sphincterotomy, stricture dilatation, stone extraction and stent placement are indicated in symptomatic patients with these pathologies (Strobel et al., 2009).

Apart from pain, chronic pancreatitis might also cause pseudocyst formation, leading to abscess, ascites and pleural effusion secondary to rupture and occasionally pseudoaneurysm formation. The formation of pseudoaneurysm could in turn lead to massive gastrointestinal tract bleeding or interperitoneal haemorrhage (Lai et al., 1997). Therefore, drainage of pseudocyst is another common indication for endoscopic treatment.

Recently, pancreatic neuritis secondary to inflammatory infiltration and hypertrophy of pancreatic nerves was proposed as the alternative mechanism causing abdominal pain in chronic pancreatitis (Strobel et al., 2009). Endoscopic ultrasound-guided celiac plexus block 
had been employed safely for pain relief in chronic pancreatitis with minimal complication (Avula \& Sherman, 2010; Puli SR et al., 2009).

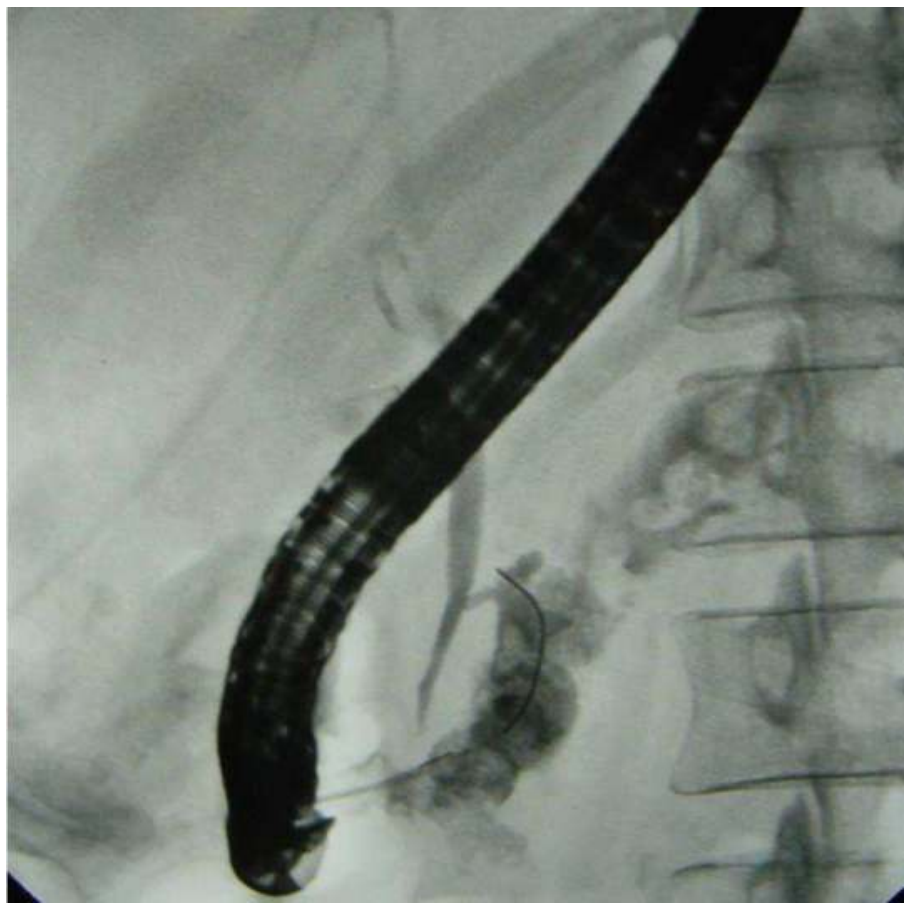

Fig. 1. Multiple pancreatic ductal stones with ductal dilatation on ERCP.

Although indications of endoscopic therapy to chronic pancreatitis might extend with more data coming up, it has little role in asymptomatic main pancreatic duct dilatation at the moment. There has been no data to suggest the restoration of the pancreatic outflow can delay the process of pancreatic parenchymal atrophy or improve the endocrine and exocrine function of pancreas (Frulloni et al., 2010).

\section{Techniques of endoscopic treatment}

With the advance in technology and improvement in endoscopic skills, various endoscopic therapies in chronic pancreaittis are made possible. The following sections described the common techniques used in chronic pancreaitits.

\subsection{Endoscopic sphincterotomy}

Endoscopic sphincterotomy can be performed by either standard pull-type sphincterotomy after wire-guided cannulation or pre-cut on pancreatic stent (Buscaglia \& Kalloo, 2007). However, unlike biliary sphincterotomy, the direction of pancreatic sphincterotomy should be directed towards the 1 to 2 o'clock position of the papillary orifice. An incision of 5 to $10 \mathrm{~mm}$ in length is usually made with the pure cutting current, so that damage to the pancreas and 
subsequent stenosis of papilla can be avoided. A pancreatic stent is usually put in temporarily to prevent ductal obstruction by post-sphincterotomy edema (Buscaglia \& Kalloo, 2007).

Occasionally pathology at the minor papilla such as pancreatic divisum, can be a cause of chronic pancreatitis (Tarnasky et al., 1997). Minor papillotomy, dividing only the mucosal mound rather than true sphincterotomy, can be performed to achieve decompression of the dorsal duct (Buscaglia \& Kalloo, 2007). A soft tip 0.035 inch hydrophilic guidewire is generally used for wire-guided cannulation. After deep cannulation achieved, standard pull-type sphincterotomy can be performed, directing along the course of the dorsal duct, usually at $11 \mathrm{o}^{\prime}$ clock position (Buscaglia \& Kalloo, 2007).

Endoscopic sphincterotomy can also be performed as the primary treatment for conditions leading to chronic pancreatitis, e.g. sphincter of Oddi dysfunction. It is, however, more commonly used to gain access to the pancreatic duct and facilitate further endoscopic treatment as described in later section.

\subsection{Pancreatic ductal dilatation and stenting}

Patients with focal main pancreatic duct stricture at the head or body can be managed by dilatation and stenting, usually after pancreatic sphincterotomy. A guidewire can be passed proximal to the stricture site, over which graduated dilating catheter or hydrostatic balloon dilator can be used for stricture dilatation. Since these strictures from chronic pancreatitis are very fibrotic, simple dilatation alone usually does not give long term response (Yoo \& Lehman, 2009). Endoscopic stents are therefore placed across the strictures to adequately expand the lumen to achieve a good flow of pancreatic juice even after the stent is removed. Different sizes of stents are used for different purpose, but they should not be larger than the diameter of the distal duct. In general, stents for pancreatitis prophylaxis are usually 3-5 Fr in size, whereas single or multiple stents up to 7 to 10 Fr might be necessary after stricture dilatation (Yoo \& Lehman, 2009). The optimal duration to leave a stent in-situ is not known

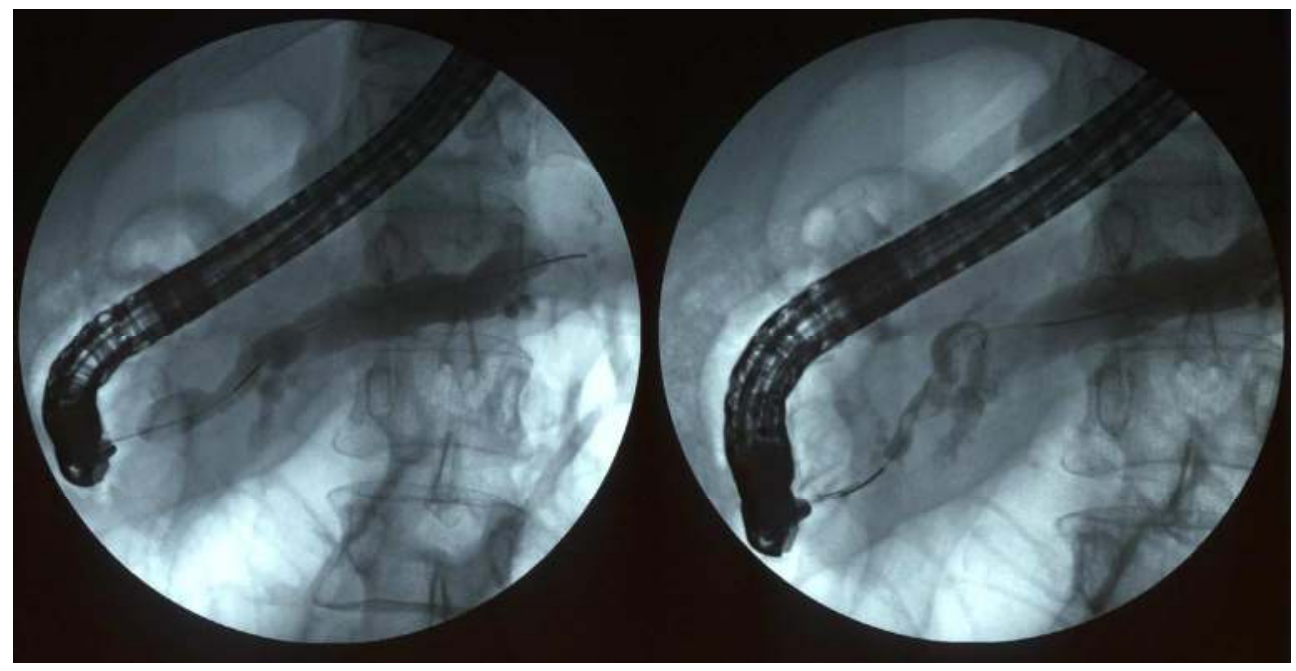

Fig. 2. Pancreatic ductal stricture dilatation with balloon dilator. 
(Sherman \& Lehman, 1998). It can be left till symptoms reappears or can be exchanged at 3monthly interval (Yoo \& Lehman, 2009). In patients with dominant pancreatic duct strictures, the technical success rate up to $91 \%$ had been reported but only $62 \%$ of these patients had symptoms improved. The morbidity and mortality rate reported were $18 \%$ and $1 \%$ respectively (Yoo \& Lehman, 2009).

\subsection{Extraction of pancreatic ductal stones}

Removal of pancreatic ductal stones usually requires a pancreatic sphincterotomy to facilitate access to the duct. In cases where strictures distal to the stones are present, dilatation with catheters or hydrostatic balloons is also required. Balloons and baskets are common accessories for stone retrieval and in difficult cases, such as bending across a tortuous duct, over-the-wire accessories might be necessary (Sherman \& Lehman, 1998). For very big and hard stones, lithotripsy either using laser or electrohydrolic lithotripsy (EHL) or extra-corporeal shock wave lithotripsy (ESWL) would frequently be necessary.

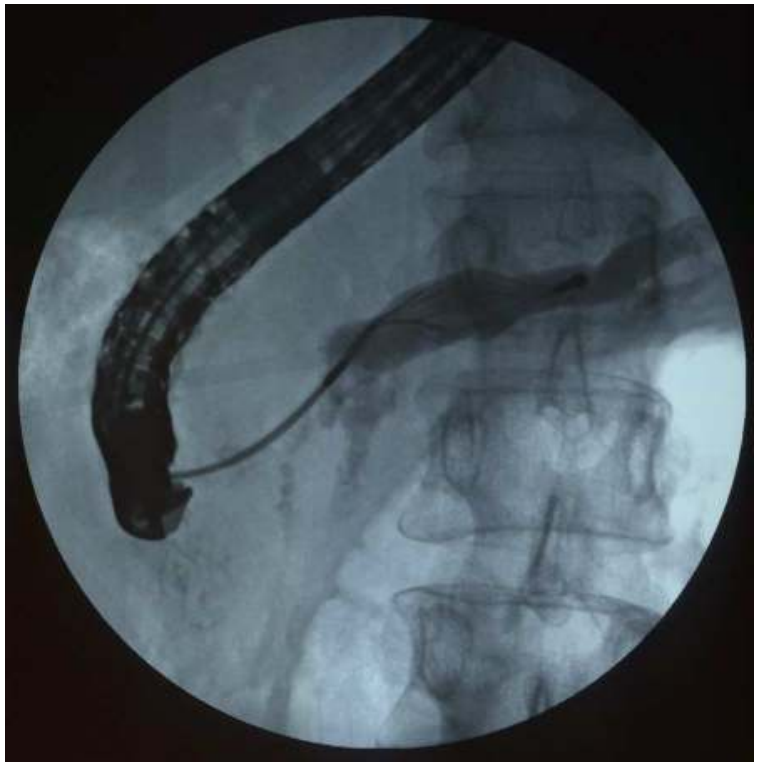

Fig. 3. Pancreatic duct stone removed with basket.

For laser or electrohydrolic lithotripsy, a small caliber through-the-scope pancreatoscope is needed to guide the lithotripsy under direct vision. The pancreatoscope can be passed down the duodenoscope over guidewire to gain access to the pancreatic duct (Howell et al., 1999). After visualization of the stone, the EHL probe or laser fibre is passed down the channel of the pancreatoscope (Howell et al., 1999; Hirai et al., 2004). In case of EHL, lithotripsy is performed with saline lavage to optimize energy penetration. Stone fragments can then be removed by basket or lavage over balloon catheter. A stent without forward flap is usually placed temporarily at the end of procedure to facilitate drainage (Howell et al., 1999). 


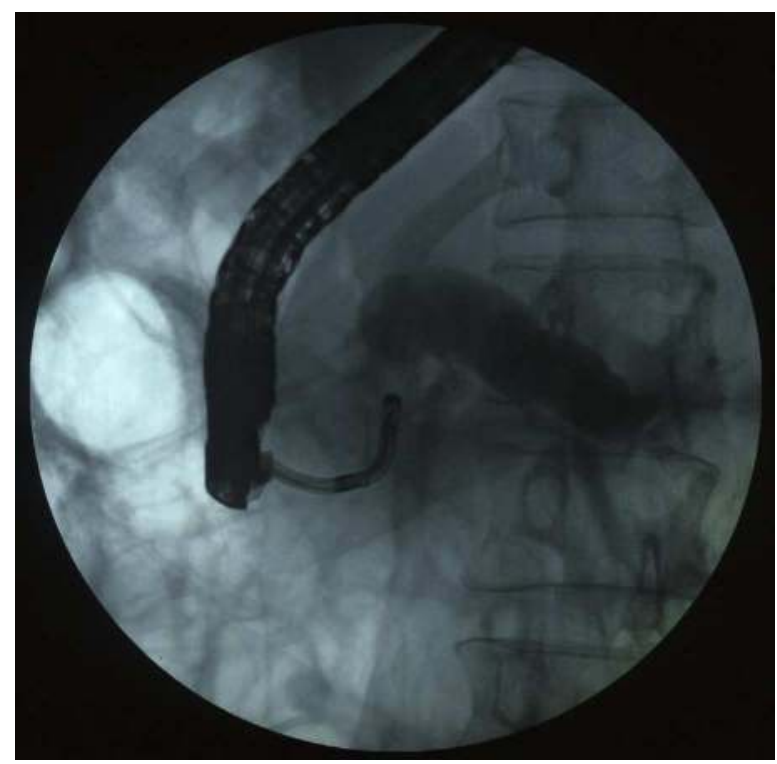

Fig. 4. Pancreatoscope passed down through standard duodenoscope to visualize the pancreatic duct lumen.

\subsection{Combined endoscopy and extracorporal shockwave lithotripsy}

Extracorporeal shock wave lithotripsy (ESWL) is another adjunct in the endoscopic treatment of pancreatic duct stones (Lawrence et al., 2010). It can fragment the stones and reduce stone burden, thus facilitating endoscopic clearance of the pancreatic duct. Endoscopic sphincterotomy is usually performed before ESWL. Pancreatic duct stones can be localized either by fluoroscopy or ultrasonography during lithotripsy. Contrast instillation through a nasopancreatic drain could sometimes help with the localization of radiolucent stone (Choi \& Kim, 2006). Occasionally the nasopancreatic drain can also be used for saline irrigation (Costamagna et al., 1997) and obtain follow-up pancreatograms after ESWL. If pancreatic ductal strictures are present, dilatation and stenting might be performed to facilitate ductal clearance and decompression after stones fragmentation (Choi \& Kim, 2006).

\subsection{Drainage of pancreatic pseudocyst}

Endoscopic drainage of pseudocyst involved the creation of communication between the pseudocyst and gastrointestinal lumen, so that the cyst content can be drained internally (Sherman \& Lehman, 1998). The access to the pseudocyst can be guided by means of endoscopic ultrasound (EUS). This facilitate transmural needle placement even when no bulge can be seen through the endoscope and avoid puncturing the vessels on gastroduodenal wall. 


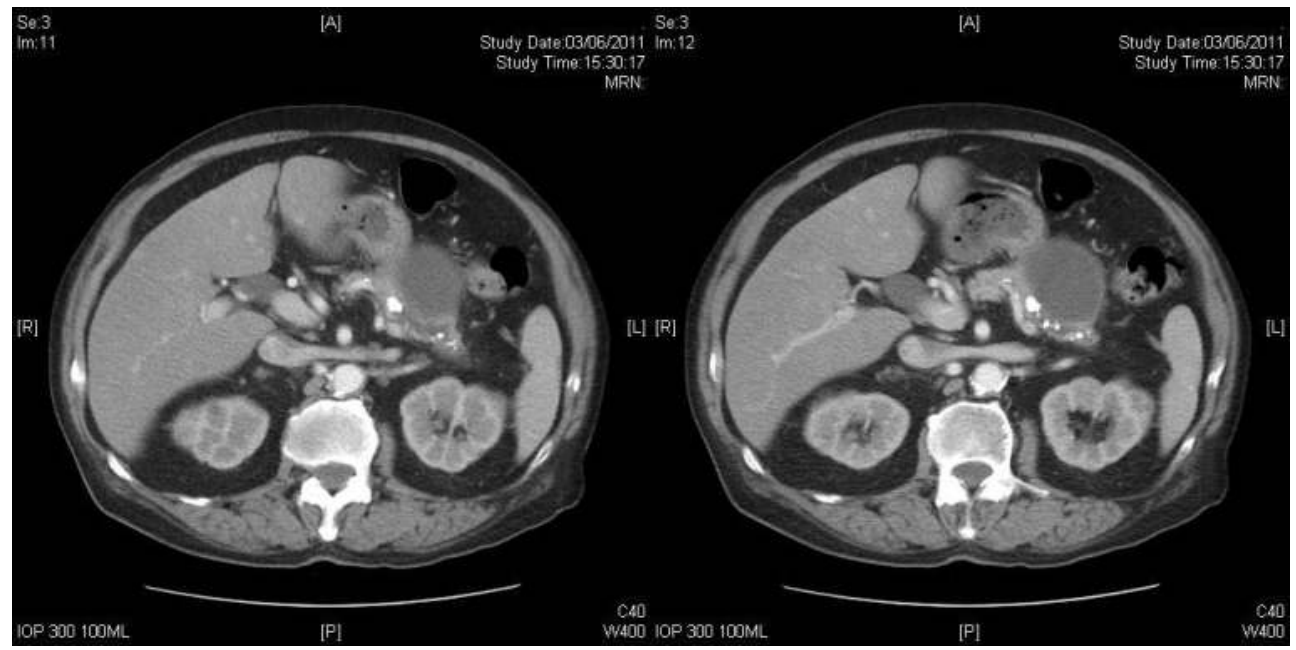

Fig. 5. Computed tomography showing pseudocyst near the tail of pancreas with mild pancreatic duct dilatation and stones proximal to the cyst.

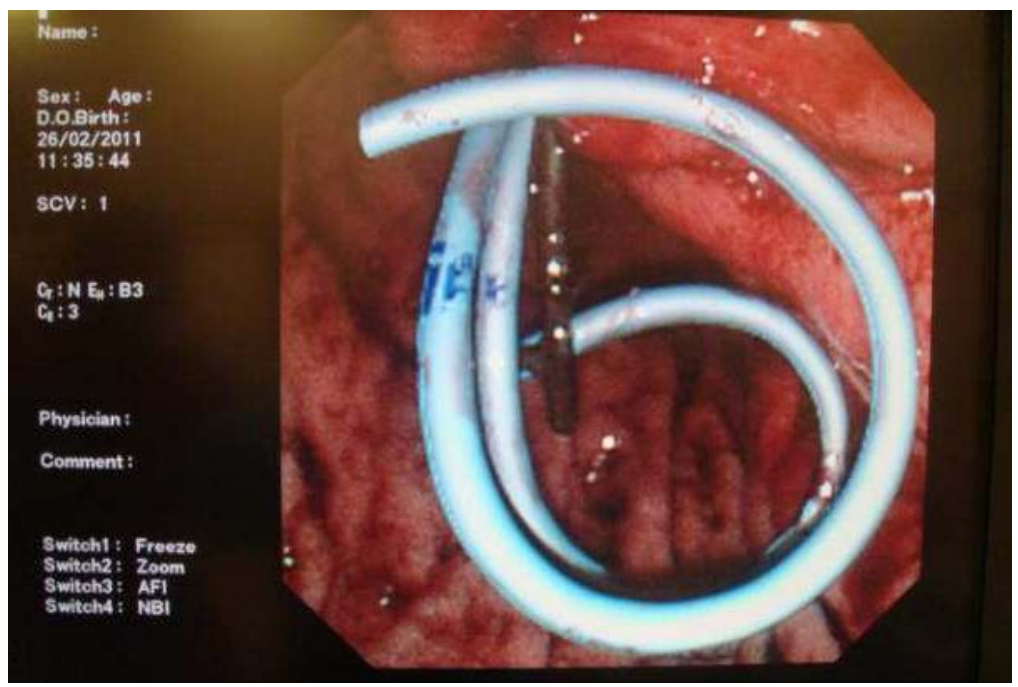

Fig. 6. Endoscopic view of plastic stent and double pigtail catheters inserted under endoscopic ultrasound guidance to form a cystogastrostomy. 
The pseudocyst is punctured under the guidance of a linear echoendoscope. A guidewire is passed into the cyst under fluoroscopic control to form at least 2 loops. The cystogastrostomy or cystoduodenostomy is then dilated with balloon catheter to $6-8 \mathrm{~mm}$ size, follow which a double pigtail stent will be inserted over the wire to establish the drainage. Second or multiple stents will then be inserted under endoscopic and fluoroscopic guidance by recannulation of the pseudocysts (Seewald et al., 2009). In case of abscess or debris are present inside the pseudocyst, saline irrigation and aspiration of the cyst content can be achieved through a nasocystic catheter instead of internal stent.

As recannulation of the pseudocyst can sometimes be cumbersome, some endoscopists advocated the use of "double-wire" technique, in which 2 wires were inserted into the pseudocyst through a double lumen catheter after the pseudocyst is punctured. Simultaneous stents or nasocystic catheters insertion can then be performed under fluoroscopic guidance over the 2 wires in place. (Itoi et al., 2009)

Complications of EUS-guided drainage include bleeding, perforation and infection. Coagulopathy has to be corrected and prophylactic antibotics should be given before the procedure. Only pseudocyst with mature wall and within $1 \mathrm{~cm}$ from gastrointestinal lumen should be considered for endoscopic drainage (Seewald et al., 2009).

Although EUS-guided drainage is a promising technique for decompression of pesudocyst in chronic pancreatitis, case selection is very important for success. Technical success rate, defined as the feasibility of access and drain insertion to the cystic fluid (Seewald et al., 2009), ranged from $92 \%$ to $100 \%$. However, up to $23 \%$ of pseudocyst recurred during a median follow-up period of 22 months (Binmoeller et al., 1995), giving a long term success rate of $65 \%$ to $81 \%$ (Aghdassi et al., 2008). In case of fail endoscopic treatment, unfavourable cyst location, such as far from the gastrointestinal lumen, or if neoplasm cannot be excluded, surgery is still the standard procedure of choice (Baillie 2004). Surgical drainage procedures can be in form of cysto-gastrostostomy or cysto-jejunostomy depending on site of the cyst. For pseudocyst masquerading cystic neoplasm, distal pancreatectomy or pancreatoduodenectomy should be advised (Cheung et al., 2008).

\subsection{Endoscopic ultrasound-guided celiac plexus block}

Celiac plexus is located at T12 to L1 level near the take off of celiac trunk adjacent to the aorta. It is a network of ganglia and nerves that lie on both side of the aorta. It contains sympathetic and parasympathetic fibres transmitting signals to and from visceral organ including pancreas. Nociceptive fibres transmitting pain also travel through the celiac plexus. Endoscopic ultrasound allows direct visualization of the celiac plexus region and can even localise the celiac ganglion (Castillo-Roth \& Gress, 2010). This enables celiac plexus block to be performed successfully and safely as a non-pharmacological means for pain relief (Avula \& Sherman, 2010).

A linear endoendoscope is used to localise the celiac plexus. It's usually found by passing the endoscope to the posterior lesser curve of gastric fundus and tracing down the aorta to locate the celiac artery take-off at about 40 to $50 \mathrm{~cm}$ from incisors. Doppler mode can be utilised during the block to ensure the absence of vessels in the path of needle insertion 
(Castillo-Roth \& Gress, 2010). A 22-gauge or 19-gauge EUS fine needle aspiration needle is passed through the biopsy channel towards the celiac axis until the tips is inserted to the level of the celiac trunk. After removing the stylet of the needle, a $10 \mathrm{ml}$ syringe is attached to the needle system. Aspiration is then applied to ensure the needle is not inside a blood vessel. Bupivicaine and then triamcinolone are then injected in the celiac space after safe needle position is confirmed (Avula \& Sherman, 2010). The agent for celiac plexus block can be injected either bilaterally on both sides of the celiac artery origin or just anterior to the take-off of celiac artery and allow the solution to spread to both sides of the vessels (CastilloRoth \& Gress, 2010). It was shown in randomised controlled trial that there was no difference in the technical success, symptom relief and complication rate between bilateral or single site injections (Leblanc et al., 2009). With the advance in endosonographic imaging, localisation of the celiac ganglia and direct ganglia block is possible. While initial data suggested that this approach was safe and effective in initial pain control (Levy et al., 2008), more studies were awaited to evaluate its long-term efficacy and the optimal drugs to be delivered as compared to conventional percutaneous celiac plexus block.

Concerning the overall efficacy in pain control by EUS-guided celiac plexus block, a metaanlysis showed that approximately $60 \%$ of patients reported pain relief after the procedure (Pauli et al., 2009). The exact intensity of pain relief and duration of pain control, however, were not described in the metaanalysis. In a series of 90 patients (Gress et al., 2001) receiving EUS-guided celiac plexus block, only $10 \%$ of patients had sustained pain reduction at 6 months. This result suggested that further studies on optimal drugs and treatment regimen would be necessary to improve the success rate. In case of refractory pain despite reinterventions, referral to surgery should be considered.

\section{Efficacy of endoscopic treatment}

Owing to the variety of endoscopic therapy available and the heterogenous nature of the underlying chronic pancreatitis, outcome of endoscopic treatment has to be considered judiciously. In a retrospective review of 125 patients with 324 intraductal stones (Farnbacher et al., 2002), the technical success rate, as defined by stone fragmentations, was reported to be $85 \%$. However, many of these patients required repeated endoscopic intervention plus ESWL. The complete duct clearance rate was only $51 \%$, whereas, $34 \%$ patient had partial clearance. For clinical success rate, defined as pain free after treatment, $52 \%$ of patients developed relapses of pain and were hospitalized again for treatment. The causes of recurrent pain were mostly due to recurrent stones or malfunction of the pancreatic stents inserted. Thirteen percent of patients in the series required subsequent surgery due to intractable pain after unsuccessful endoscopic treatment.

There were two randomised controlled trials comparing endoscopic treatment to surgical treatment in patients with chronic pancreatitis and pancreatic ductal stones (Dite et al., 2003; Cahen et al., 2007). Both studies concluded that surgery was superior to endoscopic treatment in achieving long term pain control, but they still recommended the use of endoscopic treatment in some selected cases of chronic pancreatitis with less severe ductal obstruction. The techniques employed in the endoscopic treatment arm in these 2 studies had been criticised. The endoscopic arm in study by Dite et al. did not received ESWL, 
whereas the endoscopic arm in study by Cahen et al. used stents without side-holes. The latter study was also criticised by the small sample size of total 39 patients (Deviere et al., 2008). Because of the limitation in the randomised controlled studies, endoscopic treatment still played an important role in the management chronic pancreatitis, especially in patients unfit for surgery or refusing surgery (Frulloni et al., 2010). Endoscopic treatment can be proposed as first-line treatment for the following reasons (Khanna \& Tandon, 2008) - firstly, it is less invasive than surgery; secondly, it can be repeated in case of relapse of pain; and thirdly, surgery can still be performed in refractory disease as a salvage manoeuvre.

\section{Conclusion}

Endoscopic therapy can be employed to alleviate pain in patient with chronic pancreatitis. Different endoscopic techniques, including sphincterotomy, stenting, stricture dilatation, stone removal and the insertion of nasopancreatic drain combined with extracorporal shock wave lithotripsy had been described with successful results. The use of endoscopic ultrasound-guided drainage of pseudocyst and celiac plexus block were also important alternative to surgical treatment. With the advance of endoscopic equipment, improvement of techniques and a better understanding of the pathophysiology of chronic pancreatitis, endoscopic treatment might provide patients a less invasive and comparably effective choice of therapy. However, not all patients were rendered sustained symptomatic relief. Patients with persistent pain or pancreatic mass suspicious of malignancy should be referred for consideration of surgical treatment.

\section{References}

Aghdassi A, Mayerle J, Kraft M, Sielenkämper AW, Heidecke CD, Lerch MM. (2008) Diagnosis and treatment of pancreatic pseudocysts in chronic pancreatitis. Pancreas, Vol. 36, No.2, (March 2008), pp. 105-112, ISSN 0885-3177

Avula H \& Sherman S. (2010) What is the role of endotherapy in chronic pancreatitis? Therapeutic Advances in Gastroenterology, Vol. 3, No. 6, (November 2010), pp. 367382, ISSN 1756-283X

Baillie J. (2004) Pancreaitic pseudocysts (Part II) Gastrointestinal Endoscopy, Vol 60, No. 1, (July 2004), pp. 105-113, ISSN 0016-5107

Binmoeller KF, Seifert H, Walter A, Soehendra N. (1995) Transpapillary and transmural drainage of pancreatic pseudocysts. Gastrointestinal Endoscopy, Vol. 42, No. 3, (September 1995), pp. 219-224, ISSN 0016-5107

Buscaglia JM \& Kalloo AN. (2007) Pancreatic sphincterotomy: Technique, indications, and complications. World Journal of Gasgtroenterology, Vol.13, No.30, (August 2007), pp. 4064-71, ISSN 1007-9327

Cahen DL, Gouma DJ, Nio Y, Rauws EA, Boermeester MA, Busch OR, Stocker J, Lameris JS, Dijkgraaf MG, Huibregtse K \& Bruno MJ. (2007) Endoscopic versus surgical drainage of the pancreatic duct in chronic pancreatitis. New 
Endland Journal of Medicine, Vol. 356, No. 7, (February 2007), pp. 676-684, ISSN 0028-4793

Castillo-Roth A \& Gress F. (2010) Endoscopic ultrasound-guided celiac plexus block and celiac plexus neurolysis, In: Endoscopic Ultrasound, Shami VM \& Kahaleh M, pp. 425-440, Humana Press, ISBN 978-1-0327-479-1, New York, USA

Cheung YS, Lee KF, Wong J, Ng WW, Chan MF, Chan CK \& Lai PB. (2008) Pseudocystectomy: an unusual operation for an atypical pancreatic pseudocyst, Surgical Practice, Vol. 12, No. 1, (February 2008), pp. 30-33, ISSN 1744-1633

Costamagna G, Gabbrielli A, Mutignani M, Perri Vincenzo, Pandolfi M, Boscaini M \& Crucitti F. (1997) Extracorporeal shock wave lithotripsy of pancreatic stones in chronic pancreiatitis: immediate and medium-term results. Gastrointestinal Endoscopy, Vol. 46, No.3, (September 1997), pp. 231-236, ISSN 0016-5107

Choi KS \& Kim MH. (2006) Extracorporeal shock wave lithotripsy for the treatment of pancreatic ductal stones. Journal of Hepato-Biliary-Pancreatic Surgery. Vol. 13, No. 2, (April 2006), pp. 86-93, ISSN 1868-6974

Dite P, Ruzicka M, Zboril V \& Novotny I. (2003) A prospective, randomized trial comparing endoscopic and surgical therapy for chronic pancraitits. Endoscopy, Vol. 35, No. 7, (July 2003), pp553-558, ISSN 0013-726X

Farnbacher M, Schoen C, Rabenstein T, Benninger J, Hahn E \& Schneider T. (2002) Pancreatic duct stones in chronic pancreatitis: criteria for treatment intensity and success. Gastrointestinal Endoscopy, Vol. 56, No. 4, (October 2002), pp. 501-506, ISSN 0016-5107

Frulloni L, Falconi M, Gabbrielli A, Gaia E, Graziani R, Pezzilli R, Uomo G, Andriulli, Balzano G, Benini L, Calculli L, Campra D, Capurso G, Cavestro GM, Angelis CD, Ghezzo L, Manfredi R, Malesci A, ariani A, Mutignani M, Vntrucci , Zamboni G, Amodia A \& Vantini I. (2010) Italian consensus guidelines for chroni pancreatitis. Digestive and Liver Disease, Vol. 42 Suppl. 6, (November 2010), pp. S381-S406. ISSN 1590-8658

Gress F, Schmitt C, Sherman S, Ciaccia D, Ikenberry S, Lehman G. (2001) Endoscopic ultrasound-guided celiac plexus block for managing abdominal pain associated with chronic pancreatitis: a prospective single center experience. The American Journal of Gastroenterology, Vol. 96, No. 2, (2001), pp. 409 - 416, ISSN 00029270

Hirai T, Goto H, Hirooka Y, Itoh A, Hashimoto S, Niwa Y \& Hayakawat. (2004) Pilot study of pancreatoscopic lithotripsy using a 5-Fr instrument: selected patients may benefit. Endoscopy, Vol. 36, No. 3, (March 2004), pp. 212-216, ISSN 0013726X

Howell DA, Dy RM, Hanson BL, Nezhad SF \& Broaddus SB. (1999) Endoscopic treatment of pancreatic duct stones using a $10 \mathrm{~F}$ pancreatoscope and electrophydraulic lithotripsy. Gastrointestinal Endoscopy, Vol. 50, No. 6, (December 1999), pp.829-833, ISSN 0016-5107

Itoi T, Itokawa F, Tsuchiya T, Kawai T \& Moriyasu F. (2009) EUS-guided pancreatic pseudocyst drainage: simultaneous placement of stents and nasocystic catheter 
using double-guidewire technique. Digestive Endoscopy, Vol. 21, Suppl. 1, (July 2009),pp. S53-S56. ISSN 1443-1661

Khanna S \& Tandon RK. (2008) Endotherapy for pain in chronic pancreatitis. Journal of Gastroenterology and Hepatology, Vol. 23, No.11, (November 2008), pp1649-1656. ISSN 1440-1746

Lai PB, Leung KN, Chan AC, Leok CK \& Lau WY. (1997) Case 18. Rupture of a splenic artery pseudoaneurysm into a pancreatic pseudocyst. Canadian Journal of Surgery, Vol. 40, No.6, (December 1997), pp. 412, 430. ISSN 0008-428X

Lawrence C, Siddiqi MF, Hamilton JN, Keane TE, Romagnulol J, Hawes RH \& Cotton P.B. (2010) Chronic Calcific Pancreatitis: Combination ERCP and Extracorporeal Shock Wave litotripsy for pancreatic ductal stones. Southern Medical Jounrnal, Vol. 13, No. 6, (June 2010), pp.505-508, ISSN 0038-4348

LeBlanc JK, DeWitt J, Johnson C, Okumu W, McGreevy K, Symms M, McHenry L, Sherman S \& Imperiale T. (2009) A prospective randomized trial of 1 versus 2 injections furing EUS-guided celiac plexus block for chronic pancreaitits pain. Gastrointestestinal Endoscopy, Vol. 69, No. 4, (April 2009), pp. 835-842, ISSN 00165107

Levy MJ, Topanzian MD, Wiersema MJ, Clain JE, Rajan E, Wang KK, de la Mora JG, Gleeson FC, Pearson RK, Pelaez Mc, Petersen BT, Vege SS \& Chari ST. (2008) Initial evaluation of the efficacy and safety of endoscopic ultrasound-guided direct ganglia neurolysis and block. American Journal of Gastroenterology, Vol.103 No. 1 , (January 2008), pp. 98-103, ISSN 0002-9270

Puli SR, Reddy JB, Bechtold ML, Antillon MR \& Brugge WR. (2009) EUS-guided celiac plexus neurolysis for pain due to chronic pancreatitis or pancreatic cancer pain: a meta-analysis and systematic review. Digestive Diseases and Sciences, Vol. 54, No.11, (November 2009), pp.2330-2337, ISSN 0163-2116

Schnelldorfer T, Lewin DN \& Adams DB. (2007) Operative management of chronic pancreaitits: longterm results in 372 patients. Journal of American College of Surgeons, Vol. 204, No.5, (May 2007), pp. 1039-1047, ISSN 1072-7515

Seewald S, Ang TL, Tend KC \& Soehendra N. (2009) EUS-guided drainage of pancreatic pseudocysts, abscesses and infected necrosis. Digestive Endoscopy, Vol. 21, Suppl. 1, (July 2009), pp S61-S65, ISSN 1443-1661

Sherman S \& Lehman GA (1998). Endoscopic treatment of chronic pancreatitis, In: Surgical diseases of the pancreas $3^{\text {rd }}$ Ed, Howard J, Idezuki Y, Ihse I \& Prinz R, (Ed.), pp. 343357, Williams \& Silkins, ISBN 0683180193 , Maryland, USA.

Strobel O, Buchler MW \& Werner J. (2009) Surgical therapy of chronic pancreaittiis: Indications, techniques and results. International journal of Surgery, Vol. 7, No. 4, (August 2009), pp. 305-312, ISSN 1743-9191

Tarnasky PR, Hoffman B, Aabakken L, Knapple WL, Coyle W, Pineau B, Cunningham JT, Cotton PB, Hawes RH. (1997) Sphincter of Oddi dysfunction is associated with chronic pancreatitis. The American Journal of Gastroenterology, Vol. 92, No.7, (July 1997), pp. 1125-1129, ISSN 0002-9270 
Yoo BM \& Lehman GA. (2009) Update on endoscopic treatment of chronic pancreatitis. Korean Journal of Internal Medicine, Vol. 24, No. 3, (September 2009), pp. 169-179, ISSN 1226-3303 


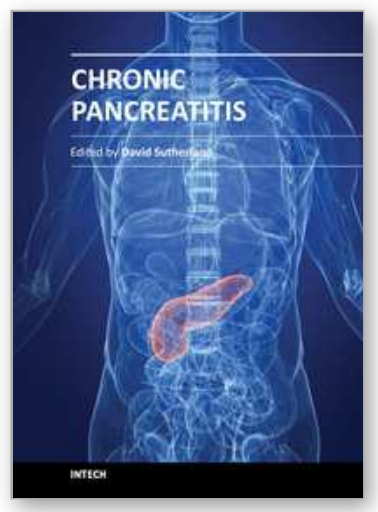

\author{
Chronic Pancreatitis \\ Edited by Prof. David Sutherland
}

ISBN 978-953-51-0011-9

Hard cover, 138 pages

Publisher InTech

Published online 15, February, 2012

Published in print edition February, 2012

Chronic pancreatitis is a disease of diverse etiologies in which pain can be devastating, severely impairing quality of life, and treatment is a challenge. This book covers cutting edge basic science research and clinical diagnosis and treatment issues in chronic pancreatitis. Basic science chapters include studies on amelioration of chronic pancreatitis in rats by bone marrow derived mesenchymal cells; on gene therapy using HSVEnkephalin to reduce fibrosis, inflammation and pain in a rats; and on pancreatic acinar and island neogenesis according to vascular and matrix dynamics of human and animal tissue. In regard to the clinical aspects, the role of endoscopic ultrasound in detecting the changes of chronic pancreatitis are addressed as well as the endoscopic treatment via duct drainage procedures or stone removal. Finally, the surgical options for chronic pancreatitis (there are well over 20 procedures) are extensively discussed, with a final chapter on total pancreatectomy and islet autotransplant to definitively remove the root cause of the pain with preservation of endocrine function. This book will be valued by basic scientists and clinicians striving to understand the mechanisms of pain in chronic pancreatitis and the treatment options in patients so afflicted.

\title{
How to reference
}

In order to correctly reference this scholarly work, feel free to copy and paste the following:

Yue Sun Cheung and Paul Bo-San Lai (2012). Endoscopic Treatment in Chronic Pancreatitis, Chronic Pancreatitis, Prof. David Sutherland (Ed.), ISBN: 978-953-51-0011-9, InTech, Available from: http://www.intechopen.com/books/chronic-pancreatitis/endoscopic-treatment-in-chronic-pancreatitis

\section{INTECH}

open science | open minds

\section{InTech Europe}

University Campus STeP Ri

Slavka Krautzeka 83/A

51000 Rijeka, Croatia

Phone: +385 (51) 770447

Fax: +385 (51) 686166

www.intechopen.com

\section{InTech China}

Unit 405, Office Block, Hotel Equatorial Shanghai

No.65, Yan An Road (West), Shanghai, 200040, China

中国上海市延安西路65号上海国际贵都大饭店办公楼 405 单元

Phone: +86-21-62489820

Fax: $+86-21-62489821$ 
(C) 2012 The Author(s). Licensee IntechOpen. This is an open access article distributed under the terms of the Creative Commons Attribution 3.0 License, which permits unrestricted use, distribution, and reproduction in any medium, provided the original work is properly cited. 